\title{
Las narraciones como nexos entre el turismo y el patrimonio cultural
}

\author{
Dr. Eloy MARTOS NúÑEZ \\ Profesor Titular Universidad. Facultad de Educación. \\ Universidad de Extremadura. \\ emarnun@gmail.com \\ Dr. Alberto E. MARTOS GARCÍA \\ Profesor contratado doctor. Facultad de Educación. \\ Universidad de Extremadura \\ aemargar@gmail.com
}

Recibido: 31/03/2011

Aceptado: 5/04/2011

\section{RESUMEN}

Se plantean en este artículo el papel de las narraciones como nexos entre el turismo y al patrimonio cultural, analizando los distintos enfoques multidisciplinares y posibles líneas de investigación. En particular, se ponen en valor los llamados enfoques narrativo.

Se ilustra el debate con una experiencia profesional llevada a cabo por iniciativa de la Consejería de Cultura y Turismo de la Junta Extremadura, destinada a crear un material promocional titulado "En los confines de Terra Extrema".

Palabras clave: turismo, patrimonio cultural, ficciones, sagas, mitos.

The stories as links between the tourism and the cultural heritage

\begin{abstract}
In this article, the role of narrations as links between tourism and cultural heritage is set out, analysing the different multidisciplinary focuses and possible research lines. Particularly, the so called narrative focuses are valued.

This debate is instructed with a professional experience taken by the initiative of the Consejería de Cultura y Turismo of the Junta de Extremadura, aimed at creating a promotional stuff called "En los confines de Terra Extrema" (In the confines of Extremearth)
\end{abstract}

Keywords: tourism, cultural heritage, fictions, sagas, myths. 
-Don Cleofás, desde esta picota de las nubes, que es el lugar más eminente de Madrid, te he de enseñar todo lo más notable que a estas horas pasa en esta Babilonia española, que en la confusión fue esa otra con ella segunda de este nombre.

Y levantando a los techos de los edificios, por arte diabólica, lo hojaldrado, se descubrió la carne del pastelón de Madrid como entonces estaba...

El Diablo Cojuelo

\section{EL MARCO TEÓRICO}

Ni siquiera la visión desde el aire que invoca Luis Vélez de Guevara en El diablo cojuelo sería suficiente para "desentrañar" Madrid, igual que no es fácil separar todas las capas u "hojaldres" que participan del concepto de patrimonio ${ }^{1}$. En efecto, éste es un concepto que ha sido cada vez más valorizado, no sólo como memoria cultural de una comunidad sino como fuente de intercambios sociales, diálogo cultural, etc. El patrimonio cultural ha pretendido ampliar la visión del patrimonio a otras manifestaciones no tan obvias como las de la cultura material, es el caso de los rituales o de la tradición oral. Paralelamente, el turismo cultural ha aprovechado el carácter multidisciplinar de esta actividad para valorizar el patrimonio cultural como una especie de plus o valor añadido del destino.

Tradicionalmente, el concepto de patrimonio histórico-cultural se ha asociado con facilidad al de patrimonio tangible porque era fácil visualizarlo como "monumentos" o "conjuntos" histórico-artístico. En cambio, urge matizar qué es patrimonio inmaterial, sobre si es realmente "intangible", y, en todo caso, ¿en qué sentido podemos hablar de patrimonio intangible? La UNESCO, a través de la Convención para la Salvaguardia del Patrimonio Cultural Inmaterial (PCI), afirmaba en su reunión de 2003 que el PCI se manifestaba, en particular, en los ámbitos siguientes:

1. Tradiciones y expresiones orales, incluido el idioma como vehículo del patrimonio cultural inmaterial;

2. Artes del espectáculo (como la música tradicional, la danza y el teatro);

3. Usos sociales, rituales y actos festivos;

4. Conocimientos y usos relacionados con la naturaleza y el universo;

5. Técnicas artesanales tradicionales.

De este modo, se refería a los usos, representaciones, expresiones, conocimientos y técnicas que las comunidades, los grupos y, en algunos casos, los individuos reconocen como parte integrante de su patrimonio cultural, con algunos requisitos:

\footnotetext{
${ }^{1}$ La territorialidad entonces no solamente es el suelo que pisa y circunda una etnia, no sólo es el entorno, el hábitat, el 'eco-sistema', sino que es sobre todo el espesor territorial de la acumulación cultural; de la propia memoria.» (Prada Alcoreza 1996: 80).
} 
- $\quad$ se transmite de generación en generación;

- es recreado constantemente por las comunidades y grupos en función de su entorno, su interacción con la naturaleza y su historia;

- infunde a las comunidades y los grupos un sentimiento de identidad y de continuidad;

- promueve el respeto de la diversidad cultural y la creatividad humana;

- cumple los imperativos de respeto mutuo entre comunidades, grupos e individuos y de desarrollo sostenible 2 .

Esta caracterización es esclarecedora, pero plantea algunos problemas importantes. Lo primero, es destacar la interdependencia del patrimonio cultural inmaterial y del patrimonio material cultural y natural, pues todas vienen a formar parte de un mismo conglomerado que debe ser visto bajo la forma de la perspectiva de una ecología cultural. Pongamos un ejemplo: en España las devociones a la Virgen María son parte de la cultura local ${ }^{3}, \mathrm{y}$, por tanto, constituyen un foco muy rico de cultos, leyendas, fiestas, romerías, músicas, etc. A menudo, la leyenda no tiene sentido sin el medio natural en el que surge, como lo atestigua el propio nombre (Virgen de la Ribera, Virgen del Robledal, Virgen de Aguasantas), y a la vez, la iconografía, la ermita o los exvotos son testimonios materiales de esta devoción.

Por tanto, cuando la UNESCO acota como secciones del PCI las llamadas obras maestras del patrimonio oral e inmaterial (aislando ciertas manifestaciones. que en el caso propuesto podrían ser los cantos o loas a la Virgen, o la procesión, o manifestaciones paralitúrgicas, como ha sido en España el Misterio de Elche, declarado por la UNESCO patrimonio mundial) o bien los tesoros humanos vivos, u otras facetas más concretas, como las lenguas en peligro o la música tradicional, no debe de olvidar el concepto dinámico e integrador de patrimonio, que abarcaría pues la cultura como una "memoria viva" (Lotman), cuyas expresiones forman un continuum.

${ }^{2}$ UNESCO: Convención para la Salvaguardia del Patrimonio Cultural Inmaterial, París, 17 de octubre de 2003.

${ }^{3}$ Velasco, H.M. "Las leyendas de hallazgos y de apariciones de imágenes. Un planteamiento de la religiosidad popular como religiosidad local", en La Religiosidad Popular. II: Vida y muerte: la imaginación religiosa, Barcelona: Anthropos, 1989, págs. 401-410 


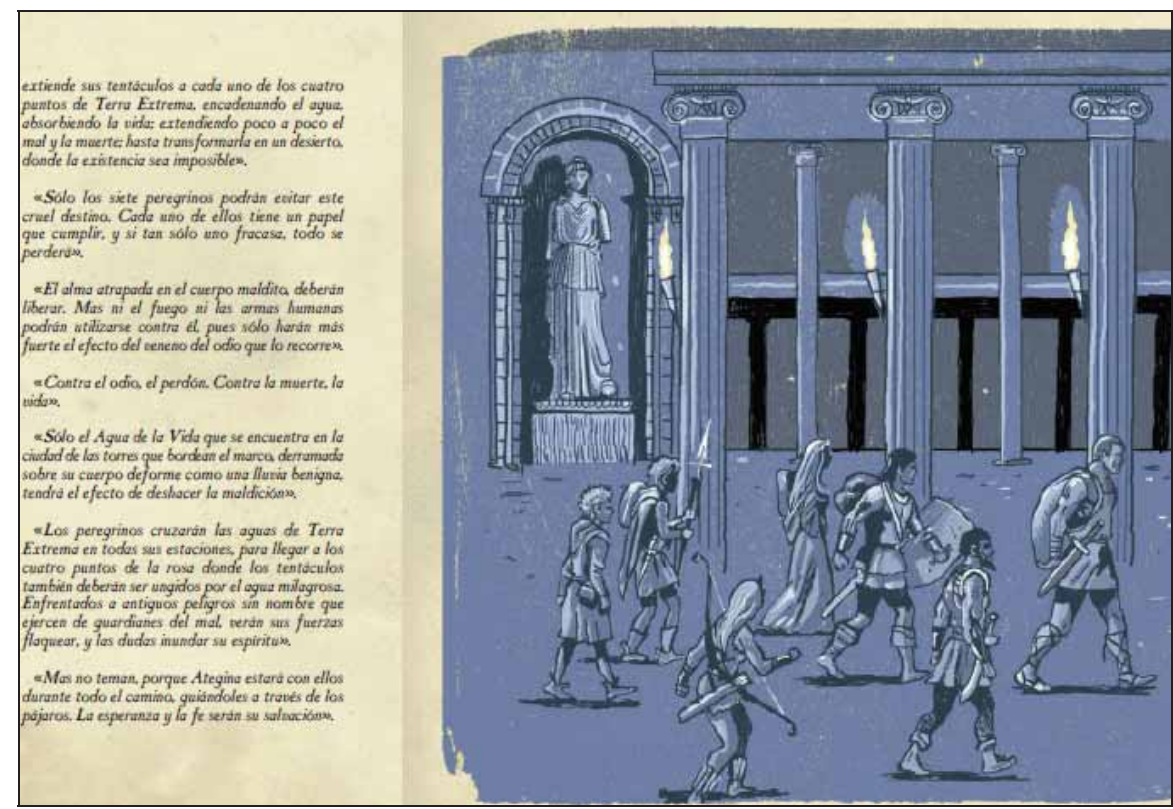

Ilustración 1 Monumentos e historias. Del libro Saga "Terra Extrema"

Es decir, el PCI es tradicional sin dejar de estar vivo, y por eso mismo, a diferencia del hieratismo del patrimonio arquitectónico, por ejemplo, está sujeto a cambios, a actualizaciones, y por eso no es tan fácil aquí utilizar el empleo de "auténtico". Una romería "auténtica" del s.XVIII es el referente pero no tiene que inspirar los nuevos usos con que la comunidad "reinviste" la fiesta, de hecho lo normal es una "remodelación coherente" (según el concepto defendido por A. Brelich) de sus elementos, que a menudo incluye una actualización de sus símbolos.

En efecto, la creencia en la Virgen María forma parte del Imaginario europeo desde hace siglos, y sus repercusiones exceden lo que es el universo propiamente cristiana, encontramos sus huellas en el folklore, el arte, la literatura, la iconografía religiosa, la arquitectura, el callejero, la toponimia, etc., etc. Pero, en cualquier caso, es un fenómeno que presenta una disparidad histórica y geográfica notable, lo cual nos lleva nuevamente a la necesidad de una consideración dinámica del PCI.

Por ejemplo, la llamada Virgen de Agosto, que se celebra en España el 15 de Agosto, abarca una multitud de fiestas patronales, en las cuales, y debido a las fechas en que se celebra, es cada vez más notable ${ }^{4}$ la forma en que el turismo, las vacaciones y otros elementos lúdicos propios de la Modernidad han afectado a estos "rituales", elementos que, por cierto, no tenían relevancia alguna en los siglos XVII ó XVIII.

${ }^{4}$ Christian, V.A. De los santos a María: Panorama de las devociones a Santuarios españoles desde principios de la Edad Media hasta nuestros días, en Temas de Antropología Española, Carmelo Lisón Coord., Akal, Madrid 
Así pues, el estudio del PCI y de su interdependencia con los otros tipos de patrimonio requiere una dosis importante de historia cultural y de interpretación actualizadora de estos usos. Algo semejante a lo que, desde el campo del patrimonio arquitectónico $^{5}$, se ha impulsado a considerar la obra constructiva como un espacio existencial, habitado y (re)interpretado, y no sólo como un espacio único o fosilizado.

\subsection{EL TURISMO CULTURAL Y LOS LUGARES "SAGRADOS". EL GENIUS LOCI}

Por tanto, en esta co-implicación de paisaje, ambiente y cultura, de materialidad y de inmaterialidad, de construcción (en el amplio sentido de la palabra) y de mentalidad, es donde reside la especificidad de este espacio singular, que a menudo se conoce como lugares de culto (por ejemplo, un santuario), pero que excede con mucho a este concepto; no olvidemos que epi-fanía es el concepto griego de revelación o sacralización de un lugar, y que quien se interesa por éste es el fanaticus, del cual deriva la noción actual de fan, de tal modo que este concepto de "entusiasta" por algo tiene sin duda un origen religioso-antropológico.

La idea normal es, en efecto, que existen lugares de culto como espacios acotados, que se corresponden con la idea por ejemplo de templo, ermita, iglesia... Sin embargo, la historia de las religiones nos habla de lugares de culto que eran a menudo espacios al aire libre, especialmente entre los pueblos semitas, que tenían espacios de culto al aire libre, usaban las plazas o bien, como en el famoso caso del tabernáculo judío, en realidad lo que tenían era un "templo portátil", que no se circunscribía, pues, a ningún espacio concreto sino que dependía de la marcha nómada de ese pueblo ${ }^{6}$. Pero incluso cuando las religiones y los cultos "se afincan", tenemos manifestaciones muy importantes de "externalización" del culto, como son las romerías, las procesiones o la Semana Santa, donde lo esencial es que el lugar de culto se amplía a un espacio mayor y mucho más participativo ${ }^{7}$. Pausanias también se refiere a ello cuando confirma que el carácter de ciudadano, de "polis", no se refiere tanto al vínculo a un territorio como a una comunidad cívica, de modo que la polis está donde están sus ciudadanos.

La conclusión de todo ello es que el turismo cultural hereda el valor con que son investidos ciertos espacios, iconos o artefactos, ya sean fijos o itinerantes, si bien lo más fácil es vincularlo a enclaves conocidos. En 1946 la Carta de Turismo Cultural adoptada por ICOMOS asociaba el turismo cultural al conocimiento de monumentos y sitios histórico-históricos. Sin embargo, la emergencia del concepto de "patrimonio oral e inmaterial" (grupo de Turín de 2001) crea una divisoria con el patrimonio "tangible", en tanto que en este patrimonio "intangible" confluirían el conjunto de memorias

\footnotetext{
${ }^{5}$ Norberg-Schulz, Christian (2007): Genius Loci. Paesaggio Ambiente Architettura. Electra

${ }^{6}$ Es también la distinción romana entre "fanum", lugar sagrado, santuario, y “templum", edificación.

${ }^{7}$ A este respecto, es muy notorio el caso de la fiesta egipcia de Opet, donde la tríada tebana salía de sus templos y era transportada en barcas hasta Luxor, para volver finalmente a su "sede" pasados unos días.
} 
colectivas, mitos, usos y costumbres, saberes y creencias, rituales y fiestas, y, en general, el patrimonio lingüístico, por ejemplo, los valores o iconos identitarios de una comunidad, que se vehiculizan y explican por la palabra y otros símbolos.

A diferencia de los bienes muebles e inmuebles que forman parte del patrimonio tangible, y que a veces son transportables, los bienes culturales "intangibles" se vinculan a menudo a un "espacio cultural", concepto que va más allá de la noción de sitio histórico-cultural (monumentos o ruinas).

Así, un espacio o paisaje cultural es una suma totalizadora que favorece una expresión popular determinada: el patio andaluz como lugar de coloquio, la plaza como ámbito narrativo-festivo, etc. Es decir, convergen en este marco la palabra (las lenguas, la literatura oral...), la ritualización festiva (música, danza, juegos...) y otros elementos de comunicación, como las derivadas de la imagen. Por ejemplo, la procesión del Corpus en ciertas ciudades es un buen ejemplo de interacción de tradición oral, manifestaciones paralitúrgicas e iconografía, en simbiosis con un "territorio" determinado. En este sentido, el Misterio de Elche es un ejemplo español emblemático de obra maestra de patrimonio oral e intangible, dentro de los 19 casos seleccionados al amparo del Masterpieces of the Oral and Intangible Heritage of Humanity, y en tal caso vemos también cómo esta realidad se ve conformada por elementos como el drama musical conservado, la basílica, la escenografía, los textos, el entorno natural (el palmeral de Elche), etc.

Por tanto, se trata de identificar formas de expresión cultural tradicional y popular, como son las mil y una tradiciones o leyendas locales, pero además vinculadas a sus propios espacios culturales, y a un marco más amplio, que a menudo es la cultura popular agraria, entendida en sentido dinámico, es decir, como un conglomerado cultural heredado que se actualiza por las influencias urbanas y de la modernidad. Las ventajas del concepto de Patrimonio Intangible es que permite integrar en un todo manifestaciones heterogéneas, como la literatura oral, los mitos o las fiestas, de forma que se pueda llevar la información en bases de datos de fácil manejo y recuperabilidad.

Por otra parte, no está claro que el patrimonio cultural sea un todo unívoco susceptible de interesar a toda clase de turistas. Agustín Santana (2003) pone el dedo en la llaga al poner en cuestión ciertas preconcepciones, como que un mayor patrimonio cultural puede activar el flujo turístico. Ciertamente, las formas alternativas de turismo, como el ecoturismo, el turismo rural o el turismo cultural, han encontrado nuevos segmentos de mercado, pero vale la pena un análisis más pormenorizado de esta cuestión.

Para algunos, el concepto de patrimonio viene a ser la síntesis de valores identitarios de una comunidad (Iniesta i González 1991), pero ni desde el punto de vista histórico, ni etnográfico ni sociológico esto se sostiene sin que haya que incluir muchas matizaciones. El turista contemporáneo, antes con las guías o mapas turísticos y ahora con Google Maps y otras aplicaciones, está acostumbrado a percibir el espacio como un continuum jalonado de ciertos hitos, como las ciudades, castillos y otro sinfín de rótulos con que se cubren estas cartografías. Sin embargo, sabemos que desde los antiguos se acotaba perfectamente el espacio en forma discontinua, marcando por ejemplo los límites de la ciudad y sus extramuros, o del espacio profano y el espacio sagrado. 
Percibir estas discontinuidades equivale a comprender los hitos del paisaje, el "alma del lugar".

Lo cierto es que los propios espacios son percibidos de forma diferente desde cada interpretación personal y cultural. Para los "autóctonos" o habitantes de un lugar, el espacio no puede ser descrito como un mapa de referencias sino más bien como una corografia, esto es, como un espacio habitado, con su centro y sus periferias, y sus puntos neurálgicos o "lugares de memoria" (Pierre Nora 2000) que se expresan a través de su historia particular, sus topónimos, etc. Conocerlos ha formado parte de un aprendizaje significativo, esto es, conectado con la experiencia, y por eso es capaz de interpretar cada signo y de integrarlos en una comprensión global.

Los etnógrafos y los arquitectos -en una curiosa convergencia- han expresado esta singularidad del lugar con un concepto religioso: el "genius loci" (Norberg-Schulz, 2007), si quiere usted captar "el alma" de un sitio pregúntele al "genius loci", es decir, la determinante fundamental de una cultura vendría a ser el "espíritu del Lugar".

Por otra parte, la naturaleza y el área misma del genius loci no es tampoco fácil de definir: simbólicamente, se identifica a menudo con el patrón, ancestro o tótem de la ciudad o del lugar, ya sea un dragón, un toro, un santo...; suele estar plasmado en el escudo, en leyendas, en el callejero, y expresa en todo caso un vínculo originario, que se plasma en una imagen codificada: por ejemplo, la loba del Capitolio amamantando a Rómulo y Remo, pues para los romanos la propia Historia de Roma se resumía en la misma Roma, en sus colinas, sus edificios, sus calles y encrucijadas. El "genio", pues, del Imperio es la propia idea de ciudad, y su apoyo es su fundación legendaria, sus lugares de memoria, sus símbolos que perpetúan precisamente esa idea de Roma Aeterna.

Las corografías han sido objeto de todo tipo de reelaboraciones, porque han sido al fin y al cabo interpretaciones que suponen distintas formas de identificación del/con el entorno. Por ejemplo, los viajeros (como los viajeros románticos que recorrieron España) siempre arrojan una luz que supone una mirada de "extrañamiento", de disonancia respecto a la mirada propia de los naturales del lugar. Surgió así el costumbrismo, lo pintoresco, lo anecdótico, que ha pervivido más allá de los escritos románticos, y que ha dado lugar a los estereotipos que se van esparciendo hasta formar tópicos asociados al lugar. Así, España y Extremadura en particular puede ser reconocida internacionalmente en ciertos tópicos diseminados, como las de ser un lugar seco, atrasado, etc.

Es verdad, los viajeros extranjeros de aquella época practicaban diversas clases de observación conforme a los estereotipos culturales que traían. Por ejemplo, el gran poeta alemán Rilke, en su epistolario, se entusiasma con Toledo pero pasa con indiferencia por Sevilla ("nada esperaba y nada me dio"), no se sabe muy bien por qué. Cuando visita la Mezquita de Córdoba, abomina de la capilla cristiana, y desde luego no expresa la misma sensibilidad de, por ejemplo, Washintong Irving en Granada. La complejidad o densidad del "genius loci" de un lugar se puede adelgazar, según los usos, para convertirse en una caricatura, en un souvenir casi paródico.

Las citadas formas de turismo alternativo deberían venir acompañadas de un esfuerzo de participación mayor $\mathrm{y}$, a menudo, de imaginación. La aproximación a un 
lugar de memoria excede a los estereotipos sobre monumentos o centros históricos. Cierto que muchos de estos turistas sólo abordan este turismo cultural "de paso", de forma digamos "oblicua "o tangencial.

Como viaje al corazón de una zona, es decir, de una corografía o entorno históricocultural, se plantea el problema de la autenticidad de la experiencia, de la réplica que busca el viajero. Como ha ocurrido con el flamenco y tantas otras expresiones culturales, el fake, el sucedáneo, la falsificación es más que común, y una de las cosas que es más frecuentes es precisamente el "fake-lore", el pseudofolklore.

Porque aunque muchos se empeñen en vehicularla, la autenticidad de la experiencia del lugar no es un producto envasable sino un constructo o una creación individual. Eso no quiere decir que lo antiguo sea siempre lo genuino, porque lo cierto es que, tal como se observa en cualquier museo etnográfico, la cultura rural misma ha ido evolucionando, de modo que cuando hablamos de tradición tenemos que aplicar una mirada polifónica (Bajtin), abarcadora, comprenhensiva de todos los elementos que se han ido aglutinando.

Las fiestas locales, los mitos identitarios, las leyendas, las personas ilustres de cada comunidad, etc. son una buena piedra de toque para detectar esta visión cerrada o abierta de la tradición. Lo que parece claro es que la mirada del viajero es radicalmente distinta, porque no está ahormada, automatizada por las preconcepciones y la historia cultural de ese lugar.

También, debido a los propios condicionantes del viaje, la percepción del lugar casi nunca es fruto de una lectura erudita sino más de alguna clase de perfomance, espectáculo, o dramatización, como lo es al fin y al cabo la fiesta local, un ritual identitario la mayor parte de las veces. Poco importa, por ejemplo, que, tal como dice Marguerite Yourcenar, las procesiones de vírgenes en la Semana Santa recuerden los rituales con Astarté, lo que cuenta es cómo la devoción popular, los cofrades, las hermandades y el pueblo en su conjunto comparten esta liturgia, y la forma en que los visitantes procesan lo que para ellos les aparece ante todo como un "espectáculo".

Incluso lo exótico está más en los ojos del que mira que en la realidad misma: lo que para el antropólogo Julio Caro Baroja está dentro de la "realidad cochambrosa" de ciertas partes de la historia de España, para ciertos viajeros ingleses o franceses, eran, en cambio, ejemplos genuinos y auténticos de bandidos valientes o mujeres fatales, como la Carmen de Merimée.

\subsection{LAS NARRACIONES COMO EJES OSTENSIVOS}

En una orientación convergente con lo anteriormente expuesto, el management narrativo es una línea de trabajo para desarrollar estrategias de comunicación ${ }^{8}$, que se ha ramificado en diversas áreas de aplicación, desde el periodismo a la educación, o desde la política al mundo de la empresa. Precisamente, en el campo específico del

\footnotetext{
${ }^{8}$ Véase "Estratega de la Comunicación y del Management Narrativo. Entrevista a Rafael Alberto Pérez", en Samuel Martín Barbero (entrev.), Re-Presentaciones: Periodismo, Comunicación y Sociedad, ISSN 0718-4263, No. 2, 2006, pags. 175-181
} 
turismo, la conexión entre management y narrativas ha dado lugar a un conjunto notable de trabajos, que podríamos ejemplificar en autores como Fesanmaier ${ }^{9}$

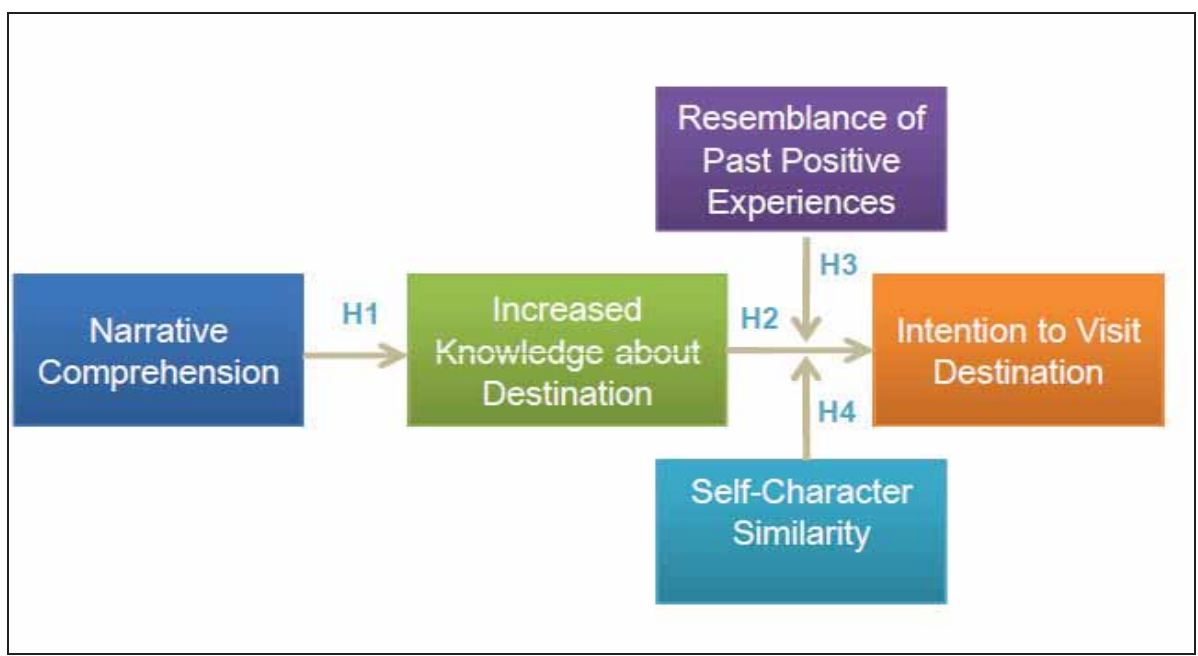

Ilustración 2 Modelo de Fesanmaier

Sin embargo, cuando hablamos de storyteller no sólo nos referimos a la herramienta, al "tool", como dice Fesanmaier, para presentar productos o servicios. Hablamos también narrativas también en el sentido psico/socio/antropológico de construcción de imaginarios, en este caso, de los propios imaginarios que los visitantes tienen acerca del destino o el producto turístico en cuestión. En este enfoque, nos preguntamos, por ejemplo, por el grado de comprensión y la intencionalidad de la audiencia en relación a los mensajes que recibe. Porque sin duda la narración es el principal mecanismo para comunicar y comprender la experiencia humana, y porque sabemos que su comprensión es algo complejo, que exige una actitud activa del receptor, el cual debe articular -sobre todo si lo enfrentamos a mensajes y experiencias nuevas- todo un proceso de apropiación o reconstrucción del sentido.

No descubrimos nada si decimos que las sagas fantásticas, al modo de El Señor de los Anillos, han tenido y siguen teniendo un auge extraordinario dentro de lo que se ha llamado industria del entretenimiento y han constituido un objeto de éxito en el mercado a través de diferentes gamas de productos: no sólo el cine o los libros, los públicos de todas las edades se han acercado a estas historias fantásticas a través del cómic, los videojuegos y otra serie de lenguajes y formatos. En suma, que son formas de ficción que gozan del favor de un público de todas las edades.

${ }^{9}$ Fesenmaier (2008): “Conceptualizing the Effectiveness of Consumer Narratives for Destination Marketing." I-CHRIE Annual Conference, Atlanta, USA, July 30 Julio. 
Por tanto, cabe la posibilidad de utilizar estos nuevos géneros expresivos de cara a nuestros objetivos. Además, dentro las historias fantásticas que tienen como base la mitología o las sagas con distintas clases de héroes y tramas, lo habitual es utilizar referentes anglosajones y no tanto de nuestra rica cultura mediterránea, es decir, se parte también de unos referentes muy estandarizados. Así, casi no hay sagas que utilicen elementos de la mitología española o mediterránea, que actualicen estos mitos con un enfoque actual, que, por poner un ejemplo, de forma que se sirvan de personajes tan emblemáticos, en el caso de Extremadura, como la Serrana de la Vera o Santa Eulalia, personajes singulares a través del cual no sólo podemos ver una comarca sino gran parte de la historia, la literatura y el folklore de Extremadura e incluso de España

Los relatos se aplican en marketing como herramienta de comunicación ${ }^{10}$ precisamente para persuadir $\mathrm{u}$ orientar la conducta de los receptores, y por tanto es importante hacer comprensible la narración. Sin embargo, el turismo cultural, por ejemplo, practica a menudo un discurso fragmentado donde se superpone lo monumental, lo arqueológico, lo literario o lo gastronómico, y se minusvalora precisamente la capacidad activa del receptor para (re)construir los mensajes que precisamente le van a interesar más.

En relación a la inteligencia narrativa se han descrito varias líneas de trabajo ${ }^{11}$, de todas la cuales nosotros queremos subrayar el papel que ejerce la construcción de narrativas a partir precisamente de ficciones fantásticas, esto es, mensajes que presentan la realidad de una forma fabulada e imaginativa, a modo del conocido género -desde Tolkien, sobre todo- de las fantasías épicas.

¿Por qué esta elección? Hay varias causas. Las fantasías épicas son un género de la ficción que en realidad hunden sus raíces en el folklore y la mitología, y permite construir mundos-réplica, espejos donde el usuario puede compartir universos en apariencia de ficción. Presentar mundos coherentes a través de personajes, cronologías y regiones más o menos "emparentadas" con el objeto de nuestro interés, generar empatías, compartir universos, es una forma "oblicua" de presentar una información, como lo es también una fábula, apólogo o alegoría, géneros que sin duda han atraído desde siempre el interés de todos los públicos.

Nótese que el turismo cultural tienen una propensión hacia lo erudito o lo museístico, cuando a lo mejor lo más fácil para la inmersión que se pretende es hacer que el visitante "resetee" todo, es decir, que parta de cero, para que precisamente pueda construir las historias con las que mejor se pueda identificar, porque, además, sabemos por los enfoques inteculturales, la dificultad de percepción de muchos contenidos que nosotros podemos estimar obvios.

La saga, el mito o la ficción fantástica, el mundo-espejo de que hablábamos, son una buena "argucia" para hablar de todo eso, porque precisamente el mito siempre tiene una lectura abierta susceptible de interesar y hacer partícipe a todos. No se trata, en todo

\footnotetext{
${ }^{10}$ Núnez, A. (2007): Será mejor que lo cuentes, Empresa Activa: Madrid.

${ }^{11}$ Fessenmaier en el artículo citado hace referencia a líneas como la "Mental simulation", las "Consumption Visions" o las “"Narrative Transportation", todas las cuales proporcionan información y modelos para evaluar mejor el producto.
} 
caso, de la nota pintoresca, del fragmentarismo, se trata de la inmersión en un universo que el visitante pueda compartir, y sin duda las tradiciones de España, por ejemplo, y de Extremadura en particular, son riquísimas por su valor etnográfico y permiten multitud de lecturas. "El toro de Coria" o la serrana de la Vera son episodios que nos remiten a mitos y rituales griegos o ancestrales, que sin duda pueden interesar a quien se acerca a ellos, aunque sólo sea por su "singularidad" respecto a la vida corriente y los imaginarios de la sociedad post-industrial.

Cuando hablamos, pues, de mitos, leyendas, rituales, canciones u otros elementos del patrimonio, no sólo hablamos de elementos sueltos del patrimonio inmaterial sino justamente en vehículos que cuentan, como en Tolkien, una historia mayor y enhebrada, con la que -si está bien contada- será fácil conectar. Además, las vinculaciones con la realidad, por muy fantástica que parezca la historia, nunca se pierden porque sabemos que la leyenda practica precisamente el discurso de la vinculación, y los anclajes en el espacio, el tiempo, los objetos, personajes o rememoranzas de hechos pasados, siempre están ahí

Con ello llegamos a un concepto clave de la antropología y de la historia: los lugares de memoria (Pierre Nora), y a una aproximación que nos interesa sobremanera: la corografía. Si combinamos lugares de memoria, corografía y mitos, obtenemos una recreación del imaginario de una comarca o zona más o menos amplio, precisamente a través de su singularidad y transversalidad. Es decir, buscamos en esa zona precisamente lo que en folklore (y también en arquitectura) se llama el genius loci, el "alma del lugar", y lo hacemos sabiendo que la tradición es polifónica, no es el relato aprendido y repetitivo de un guía de monumentos. Más bien es la actitud de Pausanias cuando visita los lugares de Grecia buscando esos ámbitos para él relevantes, las estatuas, las tumbas, los lugares de culto, las leyendas... es decir, tratando de averiguar la correspondencia de las historias que a él le habían contado con lo que puede ver en ese momento. No es pertinente aquí si Pausanias es devoto o no, si cree o no en todo aquello que cuenta, lo importante es que él selecciona un enfoque para reconocer y disfrutar de todos esos lugares de memoria, y por eso al recorrerlos indaga, los comenta, dialoga.

Con la saga que nosotros presentaremos más adelante se trataba de hacer algo parecido: una especie de guía turística sub specie fabulae. Con este material tratamos de superar la dificultad de desligar lo material de lo inmaterial en el caso concreto del patrimonio cultural que arracima monumentos y tradiciones orales, de modo que se hace preciso armonizar ambas dimensiones a través de estos nuevos conceptos. Y uno de ellos es el carácter ostensivo de tales manifestaciones:

Le terme "ostension" a eté adapté et introduit dans la terminologie folklorique anglosaxonne en 1983 par Linda Degh et Andrew Vazsonyi ("Does the Word 'Dog' Bite? Ostensive Action: A Means of Legend Telling", Journal of Folklore Research, 20, 1983: 5-34). Par les termes "action ostensible" (trad. de l'anglais "ostensive action") et "ostension", ces auteurs signifient que les legendes peuvent etre "jouees", mises en actes, autant qu'etre "racontees", mises en paroles. Par la suite, on utilise ce terme dans l'etude des rumeurs et des legendes urbaines pour designer des comportements reels d'individus qui imitent le scenario d'une rumeur ou d'une legende. Les rumeurs et 
legendes urbaines revelent souvent les peurs contemporaines. Lorsque ces histoires servent de modeles d'imitation a des criminels afin de susciter les memes peurs, on a typiquement un phenomene d'ostension ${ }^{12}$.

Esto explicaría la "modernización" de estas tradiciones, su porosidad respecto a otras vertientes del imaginario. En realidad, esta dimensión "dramatizable" de las leyendas, nos lleva a una categoría cercana, la noción artística de "perfomance" como ejecución, actuación o representación. En efecto, la Performance o acción artística puede ocurrir en cualquier lugar, iniciarse en cualquier momento y puede tener cualquier duración; una acción es cualquier situación que involucre cuatro elementos básicos: tiempo, espacio, el cuerpo del performer y una relación entre el performer y el público. Se convierten así en "narrativas en acto", esto es, enunciables en situación, en su contexto real, haciendo ese mismo papel que hacían las lecturas de los refectorios de los monasterios: acompañar el disfrute de la comida, en este caso, del viaje.

\section{EL CONTEXTO DE LA INNOVACIÓN Y LAS PROPUESTAS}

La Dirección General de Turismo de la Junta de Extremadura desarrolla una serie de programas para reforzar modalidades como el ecoturismo o el turismo idiomático. La publicación de los materiales de "En los confines de Terra Extrema", un relato de introducción a Extremadura "en clave mítico-literaria, va en esta línea de aportar por la innovación y la creatividad para presentarse como destino. Se creado un universo fantástico para dar a conocer una tierra de leyendas, a partir de una historia que pretende fascinar y atrapar al lector y en la que éste puede participar de diversas maneras. El material tiene una intención pedagógica y a la vez promocional, ya que la primera tarea que tiene Extremadura es darse a conocer como destino de turismo idiomático.

12 J.-B. Renard (1999): Rumeurs et legendes urbaines, PUF, "Que sais-je ?" 3445, , p. 125 


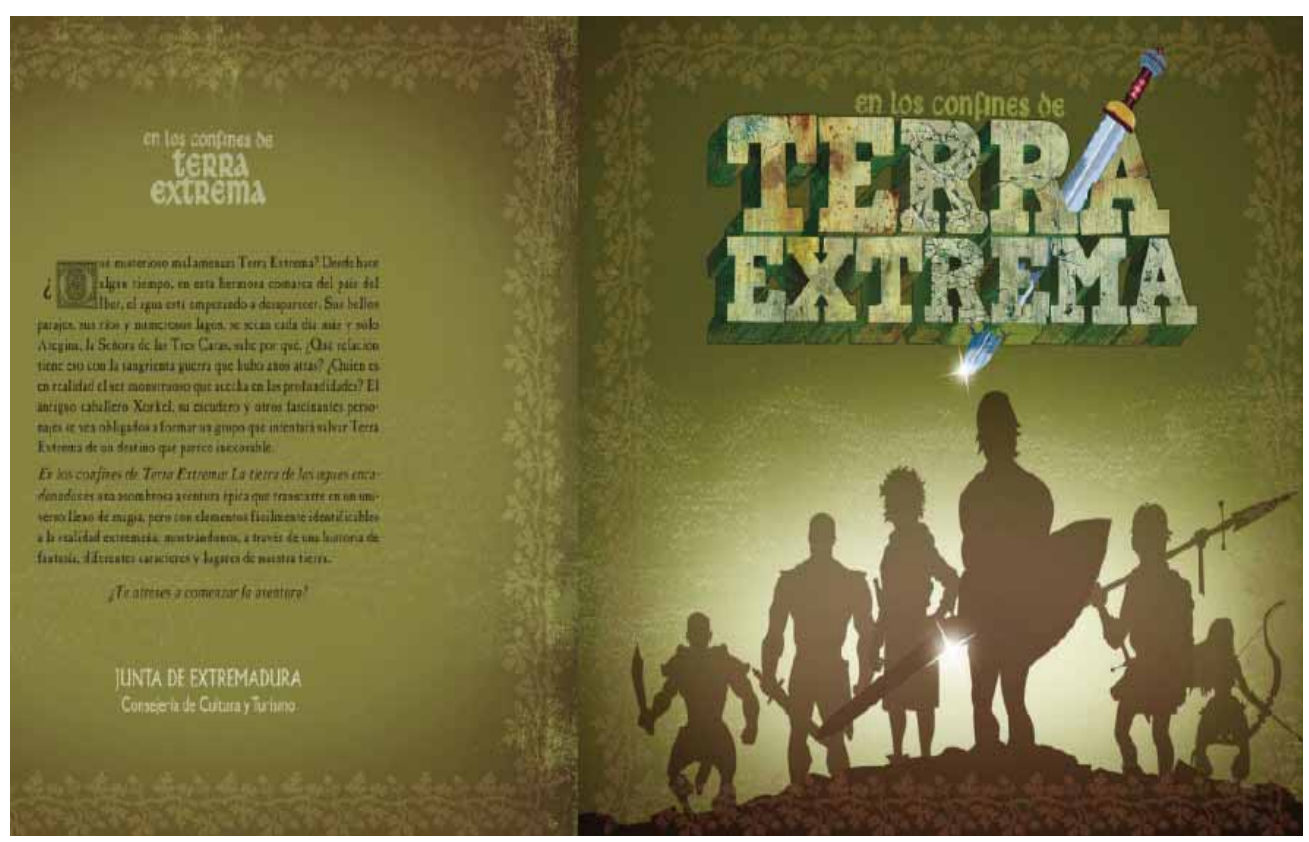

Ilustración 3 Caja de los materiales "Terra Extrema"

Pero para avanzar en el turismo idiomático, por ejemplo, hay que unir lengua y cultura, buscando precisamente la "marca", lo distintivo, que es precisamente la conjunción de naturaleza, historia y tradiciones, el "genius loci".

El Proyecto "En los confines de Terra Extrema" se enmarca, pues, en esta estrategia de presentación narrativa del destino. Se trata de combinar tres elementos básicos, turismo, patrimonio cultural y ficción o fabulación. Es ciertamente una corriente actual cada vez más pujante, la de aunar la imaginación a ciertos destinos turísticos, pero aquí no se trata de utilizar la fantasía, el misterio o el miedo para mantener en vela a los visitantes de una casa rural, por poner un ejemplo actual, sino para de buscar una especie de inmersión en lo que es una región a través de dos herramientas básicas: la lengua y la cultura. Y decimos la lengua porque se trata de usar el vehículo de la narración, no de enseñar Extremadura en el sentido de exponer, sino de contar una historia, pero no una historia cualquiera sino precisamente la que intenta trenzar una visión fabulada unitaria, tomada a partir de las claves del patrimonio y la memoria cultural de Extremadura.

Ahora bien, al elegir la ficción, las historias, como arranque de todo, los autores han tratado de ir en una dirección distinta de la habitual: de la fantasía a la historia, del patrimonio inmaterial al material, de lo poético o fabulado en un supuesto tiempo mítico a la Extremadura reciente y actual.

Así pues, la construcción de la saga o historia llamada "En los confines de Terra Extrema", perseguía, como toda saga, desarrolla su propia geografía, razas, personajes, animales, etc., que por supuesto tienen un "aire de familia" con la Extremadura real, 
aunque no pretende ser una descripción prosaica de la región o que recale en sus tópicos más conocidos, pues lo primero y principal es que el relato enganche, guste al visitante, de forma que el lector viaje al destino primero de una forma mental y luego de todas las otras formas posibles. Por eso los lugares, los nombres y todo lo demás se corresponde con los códigos de la fantasía épica más que al tipo de información expositiva y utilitaria que podemos hallar en otra clase de documentos de información turística.

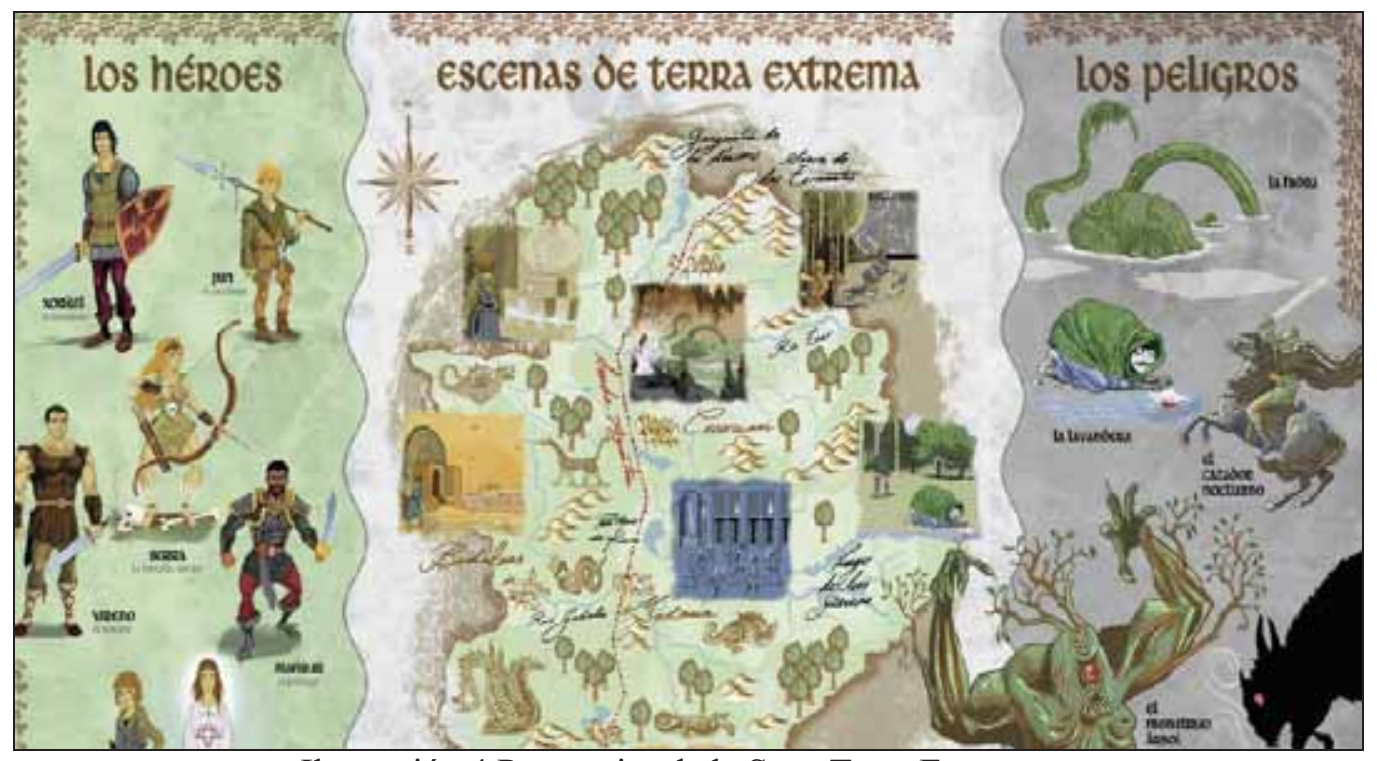

Ilustración 4 Personajes de la Saga Terra Extrema

Así, no en vano se plantea una historia mágica donde el eje principal es que Extremadura es una inmensa tierra de aguas, sí, de aguas en peligro, retenidas, encadenadas, que sólo una aventura mágica podrá volver a su armonía. Por cierto, hay otros cuentos en el folklore español que hablan también de esta magia, del agua de la vida, pero al poner como elemento principal el agua, unos lugares míticos y una aventura llena de riesgos, creo que los autores consiguen que nos identifiquemos emocionalmente con algo que en el fondo reconocemos como Extremadura.

A este respecto, cabe recordar que se han dado otros ejemplos exitosos de turismo basado en la ficción, no sólo al Código Da Vinci sino los seguidores de obras como la de Tolkien o la Barcelona de La Catedral del Mar, de Ildefonso Falcones. Por no hablar de las rutas literarias asentadas no sólo sobre best-sellers sino sobre figuras o clásicos literarios, es el caso de Bécquer, por ejemplo, y su ruta aragonesa. De hecho, las rutas literarias ha sido un exitoso programa del Ministerio de Educación que ha permitido que escolares de distintas partes de España conozcan otras comunidades a partir de ciertas singladuras, basadas en autores y obras del legado literario de cada región.

Y si Tolkien habla de la Tierra Media o de Rohan y tras ellas podemos adivinar los paisajes de Inglaterra o de Italia, en la referida saga, las referencias a mitos e historias 
ancestrales de Extremadura son continuas. El visitante y el lector que se paren a leerlo podrá buscar la correspondencia entre esas aventuras y los referentes que ya tenga, porque ya sabemos que, como explica Agustín Santana, que hay actitudes distintas, que unos leen y otros miran, pero la clave es preparar recursos rápidos y amenos, sabiendo además que a partir de un mismo patrimonio podemos organizar diversas capas o niveles de aproximación, esto es, distintas estrategias o versiones. Apostar por la fabulación, por el patrimonio inmaterial, no es, ni más ni menos, que lo que hace habitualmente la novela históricas o la novela fantástica o legendaria: hacer incursiones hacia regiones y épocas de un pasado más o menos concretos para que el lector se adentre por los entresijos de esa sociedad y esa cultura. El objetivo, en esto caso, es ayudar a que el visitante construya su propia imagen del lugar, que por definición no es la del autóctono, el historiador o el erudito.

Esto quiere decir que no precisamos siempre de una gran complejidad sino de saber evocar en el visitante experiencias culturales que integren lo intelectual, lo estético, y lo emocional. Igual que los defensores de la arquitectura moderna rescataron el concepto de "genius loci", de divinidad del lugar, para buscar la armonía de lo que se edificaba con el paisaje y la historia, nosotros también perseguimos preguntarle al "genius loci" de tantos y tantos lugares de Extremadura -no sólo de los más conocidos- por su singularidad, porque sabemos que todos estos referentes, las leyendas, los mitos, las fiestas, son también una forma efectiva de dar a conocer el destino y de atraer el interés.

A este respecto, podemos contar una anécdota un poco en paralelismo con lo que pretendemos. Una vez que César Manrique terminó toda su obra artística en Lanzarote, un niño, viendo estos increíbles paisajes, preguntó: ¿la lava vence al agua? , en una forma de fascinante de comprender y de compartir todo aquello. Este aspecto de diálogo y reelaboración activo es lo que posibilita la ficción artística, y es la que, en el caso de una saga, puede llevar a interrogantes sobre los misterios que plantea su lectura.

Además, toda buena saga, dispone de un material de acompañamiento, en este caso, mapas, posters o desplegables (donde por cierto se perciben con claridad esos dos planos que venimos aludiendo, el episodio mítico y las fotos y el calendario de la Extremadura actual, separadas, claro, por la línea del tiempo ${ }^{13}$. Precisamente, gracias a un truco de las sagas (la línea del tiempo, precuelas y secuelas, nosotros podemos desplazarnos a un momento mítico, donde no existían las ciudades actuales -aunque sí sus "clones"-, y, poco después, desplazarnos a momento históricos o modernos, como se ve en los posters y en la página web.

${ }^{13}$ En los posters se ha buscado además una relación de los eventos con un calendario natural, el de los meses, que da mucho juego en Extremadura, y que además relacionaremos con ciertos recursos del patrimonio, en particular fiestas (en principio las oficiales, las declaradas de interés turísticos) y algunos otros. Todo ello en el CD se completa con actividades, rutas y otras tareas. 


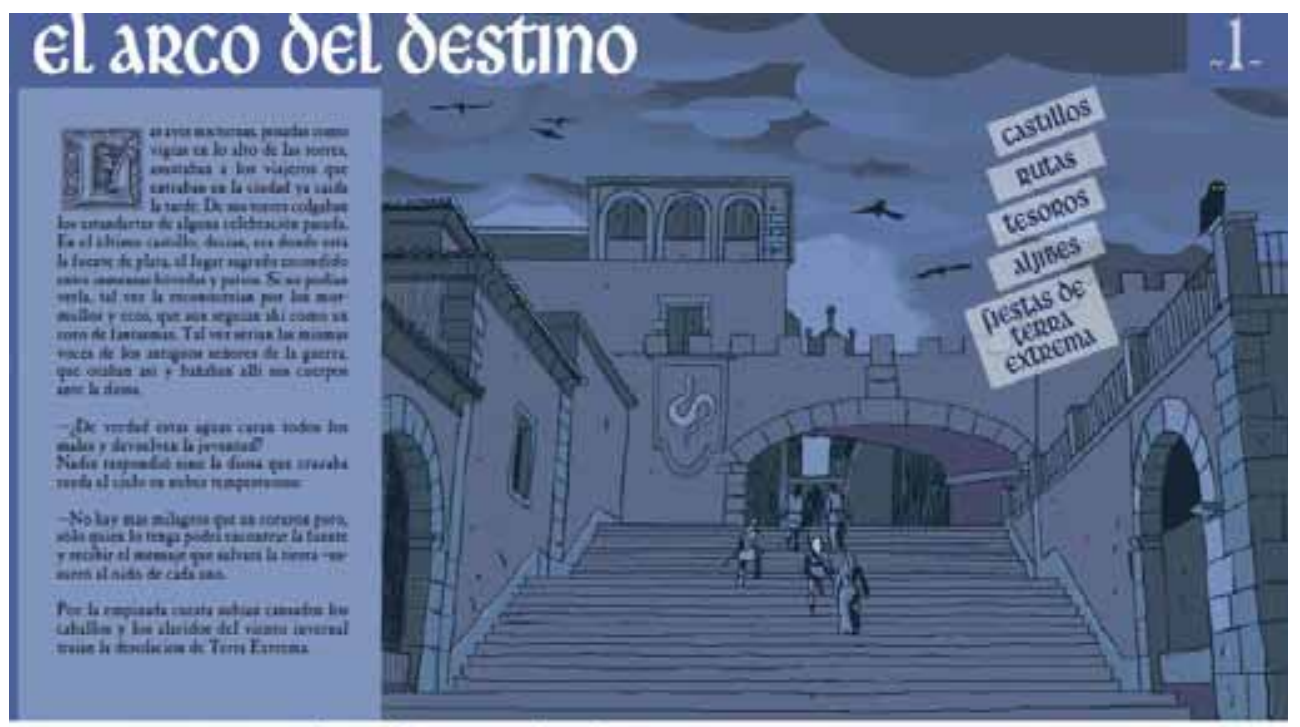

\section{La líned del tlempo}

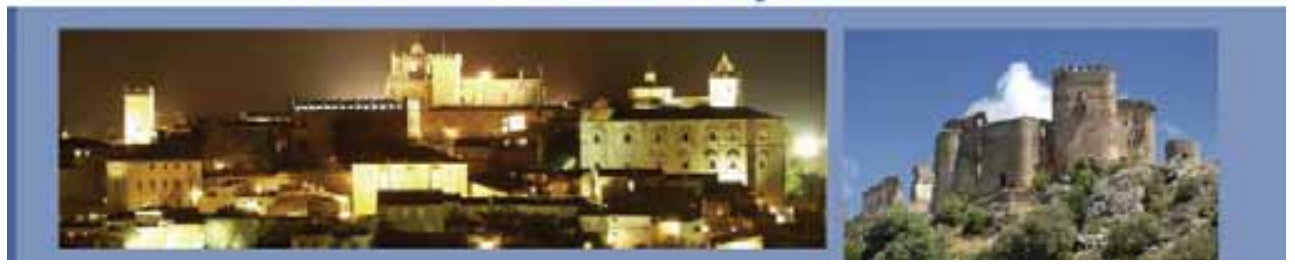

Ilustración 5 Cartel correspondiente a Cáceres

Este material se completa con una página web on line o un blog donde el público que acceda podrá encontrar ampliación de información y resolución de dudas, glosario, rutas, etc. referido todo tanto en temas de lengua como de cultura. Así que, con sólo la brújula de su imaginación y los cuatro puntos cardinales, uno puede adentrarse en este universo de Terra Extrema, una tierra de aguas, naturaleza, héroes y magia. Como tal, es un proyecto abierto, que pretende una mirada poética y centrada en los imaginarios de la tradición de Extremadura, y en esa medida pretende ser complementario a las otras estrategias y materiales puestos en marcha, como el turismo de embalses o el centrado en lagos.

Con todo esto, también se pretende poner el énfasis en el patrimonio inmaterial de Extremadura, el conjunto de mitos, leyendas, refranes, canciones, ritos, símbolos, músicas..., que la Unesco está potenciando. Conjuntos mitográficos como la Serrana de la Vera, San Jorge o Santa Eulalia no sólo son parte de nuestra memoria sino auténticos monumentos -aunque no de piedras- que debemos poner en valor.

Ciertamente, estas historias deben presentarse actualizadas a los temas, lenguajes y soportes actuales, pero sin duda tenemos a nuestro favor que una fantasía de calidad 
como la que se propone, podrá adaptar este patrimonio riquísimo de Extremadura a los fines recreativos e informativos que se pretenden. En la saga que nos ocupa no hay orcos ni hobbits ni elfos, pero sí muchas otras historias maravillosas de nuestra memoria común que contar, y además podemos y debemos contarlas para que corran de boca en boca, de visitante a visitante.

\section{CONCLUSIONES}

En resumen, vemos cómo expresiones intangibles (musicales, verbales, cinésicas...) se amalgaman con otras tangibles (vestimentas, instrumentos, inscripciones....) gracias a formatos y géneros como las sagas, y se integran dentro de una misma expresión que puede aunar información, entretenimiento, perfomance... como son las sagas que hemos comentado.

Por otra parte, la actualización en clave mítica de la herencia cultural pone de evidencia varios hechos. Por ejemplo, la preservación y el conservacionismo a ultranza propios de los ecologistas del medio natural no tienen el mismo sentido cuando nos enfrentamos al PCI, una tradición debe transformarse para conservarse, actualizarse, repetirse, ser objeto, en suma, de una "perfomance" que la refuncionalice en cada etapa, pues además una tradición oral es fuertemente inestable y fácil de contaminarse o amalgamarse con otros materiales.

Al final, el patrimonio viene a ser como un gran curso de agua: el patrimonio intangible reside básicamente en la mente humana, y es por tanto tan escurridizo como el agua; sin embargo, actúa siempre en cauces o con soportes concretos, y uno y otro (patrimonio inmaterial y material) se modelan mutuamente, como afluentes de un mismo cauce.

Las tradiciones míticas como las leyendas de Vírgenes lo expresan continuamente: a la aparición de la Virgen en un lugar determinado, normalmente en las afueras del pueblo, le sigue una orden de edificar un lugar o iglesia para su adoración; los lugareños pretenden edificar la ermita en un sitio más cercano, pero los muros se caen milagrosamente cada noche hasta que la construcción se levanta en el lugar indicado. Dicho de otro modo: es la percepción mítica, el valor que le da la comunidad a un elemento inmueble lo que hace levantar o caerse ese edificio. 


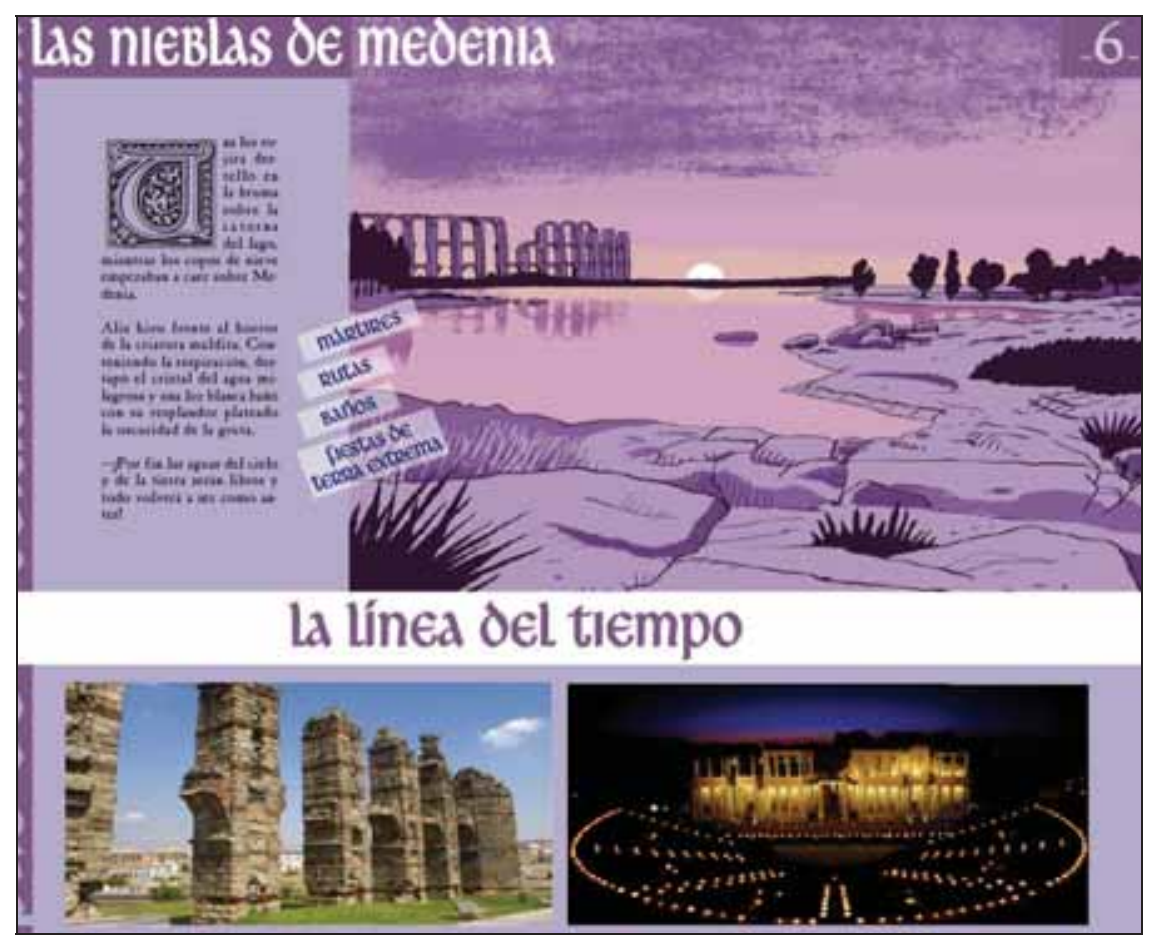

Ilustración 6 Cartel correspondiente a Mérida

En pocas palabras, nosotros somos los que, gracias en gran parte al poder de la palabra, conferimos sentido ("patrimonializamos") a los espacios y al tiempo. Ése puede ser el nexo principal entre el patrimonio cultural y el turismo.

De ese modo, la tradición es una especie de libro abierto que permite religar áreas dispersas relativas al turismo cultural, ecológico, gastronómico, de fiestas, etc. La tradición, renovada y actualizada, no es la de los estereotipos o tópicos sobre una región, sino la que se expresa en una visión polifónica (Bajtin). En consecuencia, en el caso de Extremadura, por ejemplo, no hay que acudir a la fuerza a los conquistadores, las vírgenes u otros temas más menos pintorescos para buscar su singularidad. Se trata, por el contrario, de partir de toda la riqueza de historias y tradiciones, en su multiplicidad (leyendas magia, de naturaleza, devocionales, históricas...) para armar una ficción que sirva como arranque de todo.

Con ello, no sólo se trata de construir un material de lectura, sino, como en toda buena saga, de un material susceptible de la "ostensión", esto es, que se pueda "jugar", representar o plasmar en perfomances concretas. La multimodalidad es importante, pues se puede empezar por una narración verbal pero debe abrirse a las otras narrativas, la fotografía, el vídeo o las narrativas digitales.

En todo caso, estamos primando una vía distinta, ir del patrimonio inmaterial al material y no al revés, es decir, de las historias a, por ejemplo, los conjuntos 
arquitectónicos de Mérida, Badajoz o Cáceres, que se reconocen fácilmente a pesar de toda la envoltura mítica. Por ejemplo, la figura de Santa Eulalia está unida indeleblemente al pasado romano y cristiano de Mérida, y sigue presidiendo el imaginario mítico de los emeritenses, y además constituye una mártir de una gran irradiación en todo el orbe cristiano, con todo lo que ello implica en iconografía, cultos, literatura, etc. Por tanto, conocer la basílica debería ser indisoluble a conocer en detalle su leyenda, y esto no siempre se da. Los consorcios histórico-monumentales tienen una ampliada variedad de tratamientos del patrimonio material, pero no siempre trabados a su correspondiente legado de tradiciones propias del patrimonio intangible.

Por otro lado, elegir un arranque mítico y una historia centrada en la aventuras de personajes por la "búsqueda" del agua, subrayando un escenario de aguas inmensas, permite religar ecología e historia, y de paso subrayar lo que va justamente contra el estereotipo, la idea de una Extremadura árida y sin alicientes para el viajero más allá de los tópicos de los viajeros románticos (y no tan románticos, recordemos la película de Buñuel "Tierra sin pan"), la barbarie y el casticismo.

Un material como el que se ha presentado busca un público muy amplio, personas que no conocen casi nada de Extremadura y personas que sí conocen algo, en un enfoque transversal, mezclando aspectos puramente recreativos con otros más (in)formativos. Además, el material de acompañamiento puede devenir en una especie de Atlas de Terra Extrema, que sería una guía turística en clave mítica, esto es, que, partiendo de las cuatro coordenadas, iría detallando núcleos capaces de atraer al visitante, ya sean lugares rurales (como ermitas, ríos u otros focos de interés), urbanos, históricos, monumentales, museos, etc., potenciando así una dimensión totalizadora que el visitante agradecería, del mismo modo que un español cuando visita París y en particular Saint-Denis, superpone diversas imágenes y referentes en torno a Notre Dame, desde el Sena al jorobado de Notre Dame.

Por último, no olvidemos la dimensión educativa que tienen estrategias como las que proponemos, pues sin duda una mejor educación el patrimonio, aunque fuera dentro de los parámetros de la educación informal (Light 1995), redundará en una mayor conciencia cívica y en una actitud más colaborativa por parte de todos.

\section{BIBLIOGRAFÍA}

ASHWORTH, G. J. "Heritage, tourism and Europe: A European future for European past?" En Heritage, tourism and society. D. T. Herbert (Ed.). London, Mansell Publishing, 1995. Tourism, Leisure \& Recreation: 68-84.

BAJTIN, M. por TODOROV, T. 1981: Mikhail Bakhtine, Le principe dialogique. París, Du Seuil.

BIALOGORSKI, M. y FISCHMAN, F. "Una aproximación a la dicotomía tangible/intangible en el abordaje del patrimonio cultural desde las nuevas perspectivas del folklore", Cuadernos, Diciembre, 18, 2002, Universidad de Jujuy.

CAMPBELL, J. Los mitos. Su impacto en el mundo. Ed. Eudeba, 2000. 
CARRETERO PÉREZ, A. "Museos etnográficos e imágenes de la Cultura". En Patrimonio etnológico. Nuevas perspectivas de estudio. VV.AA. (Ed.). Granada, Instituto Andaluz de Patrimonio Histórico. Consejería de Cultura. Junta de Andalucía. Editorial Comares, 1999, pp. 94-109.

CASTRO MORALES, F. y BELLIDO GANT, M.L. Patrimonio, museos y turismo cultural: claves para la gestión de un nuevo concepto de ocio. Universidad de Córdoba, Servicio de Publicaciones Editorial Complutense, S.A., 1998.

GRUFFUDD, P. "Heritage as national identity: Histories and prospects of national past". En: Heritage, tourism and society. D. T. Herbert (Ed.). London, Mansell Publishing, 1995. Tourism, Leisure \& Recreation: 49-67.

HERNÁNDEZ HERNÁNDEZ, F. El patrimonio cultural: la memoria recuperada, Gijón (Asturias), Trea, 2002

INIESTA I GONZALEZ: Los tratamientos patrimoniales del paisaje. Leer, escribir y mostrar el entorno. Universidad de Querétaro, 1991.

KIRSHENBLATT-GIMBLETT, B. Destination culture: Tourism, Museums, and Heritage. Berkeley: University of California Press, 1998.

LIGHT, D. "Heritage as informal education". En: Heritage, tourism and society. D. T. Herbert (Ed.). London, Mansell Publishing, 1995. Tourism, Leisure \& Recreation, pp. 117-145.

PRADA ALCOREZA, R. Territorialidad. La Paz, Qollana/UMSA, 1996.

SANTANA, A. "Patrimonios culturales y turistas: unos leen lo que otros miran" en Pasos: Revista de turismo y patrimonio cultural, Vol. 1, No. 1, 2003, pp. 1-12. 